\title{
Clarity and Definition in Mudejar-Gothic Churches
}

\author{
M. Galindo, T. Zamarreño, S. Girón \\ Departamento de Fisica Aplicada, Escuela Técnica Superior de Arquitectura, \\ Universidad de Sevilla, Avenida Reina Mercedes, 2, 41012 Sevilla, Spain
}

(Received 19 April 1999 and accepted 1 June 1999)

\begin{abstract}
This paper studies the $\mathrm{C}_{80}$ and $\mathrm{D}_{50}$ objective acoustic indices in relation to source-receiver distance for five different octave bands inside Mudejar-Gothic churches. This type of church, eight examples of which we have studied in the city of Seville, is characterised by good acoustic conditions as far as this can be indicated by reverberation times. This article aims to supply more data on these values and to explore the dependence of these measurements on receiver position. Finally, the experimental results have been compared with expected results derived from a semiempirical analytical model proposed.
\end{abstract}

\section{INTRODUCTION}

Mudejar-Gothic churches were probably built between the thirteenth and fifteenth centuries and they were made of brick, a material more widely available than stone on the Iberian peninsula. All these churches have similar architectural features: three naves with Moorish-style trussed roofs and a vaulted presbytery. Sendra et al.$^{1,2}$ have that the smaller size of these churches and, mainly, their wooden ceilings significantly improve their acoustics over their Gothic contemporaries.

Besides being used for worship, which implies the use of speech and music, these buildings are sometimes deconsecrated and renovated and used as lecture halls, theatres, or auditoria, especially in small provincial towns that lack other public buildings for cultural activities.

This paper reports the experimental results of clarity and definition indices at several locations in eight churches. Table 1 shows some significant data on these churches, and Figure 1 has a scale drawing of the ground plan and sections showing the architectural features of two churches. The analyses are performed in terms of both source-receiver positions and five octave bands with centre frequencies between $250 \mathrm{~Hz}$ and $4000 \mathrm{~Hz}$.

Reverberation time alone cannot predict acoustic quality in auditoria. Literature on acoustics supports the view that clarity or definition measurements determine acoustical quality of halls and auditoria. Little has been published on the effect of spatial variations on these objectives indices, and there is no evidence of an understanding of how these indices are related to other physical and acoustical properties of rooms. Apparently no one yet knows how to design a new hall so as to achieve the desired values of these parameters.

The importance of the early reflection portion of a sound decay process in an enclosed space with respect to degree of clarity, reverberation, and spatial effect is well established, so it would be advantageous to have some simple equations to calculate these character- 
istics at any reception point. After consulting the literature in this area, we perceived the difficulty of predicting these parameters without using expensive scale or computer models. The reason for this is that these parameters are very sensitive to changes in the early reflection sequence, which depends largely on the shape of the room, its surface treatments, and the relative location of the perception points.

For example, Perloson et al. ${ }^{3}$ see the relevance of the $\mathrm{C}_{80}$ acoustic parameter for analysing the acoustic quality of a room and state that this parameter can also describe seat to seat variations. When Barron ${ }^{4}$ published $\mathrm{C}_{80}$ measurements under balcony overhangs in concert halls to establish the acoustic effect of these balconies, the values of this parameter at middle frequencies exceeded the predictions of his own revised theory ${ }^{5,6}$; the average increase is $2.6 \mathrm{~dB}$. Pirn ${ }^{7}$ also establishes that clarity measurements at several distances in three music halls are inconsistent with the Barron or diffuse field predictions. Gade ${ }^{8}$ averages frequencies and positions for thirty-two famous European concert halls to assign each concert hall $\mathrm{a}_{80}$ value (in addition to other acoustic parameters he assigns). Gade compares these results with the values derived from the classical diffuse field model; clarity shows the lowest correlation.

Neither is it clear which frequency range interests us in the study of these parameters in rooms because Barron' states that his model is valid only for comparing the average middle frequencies $(500 \mathrm{~Hz}, 1 \mathrm{kHz}$ and $2 \mathrm{kHz})$. Bradley ${ }^{10}$ measures a $\mathrm{C}_{35}$ clarity index at 1000 $\mathrm{Hz}$ as a function of distance. Marshall ${ }^{11}$ studies the $\mathrm{C}_{50}$ and $\mathrm{C}_{80}$ parameters from five positions in a large auditorium. He associates $\mathrm{C}_{50}$ with an early to late ratio for speech and therefore supplies weighted averages in the $0.5,1,2$ and $4 \mathrm{kHz}$ bands. Similarly he associates $\mathrm{C}_{80}$ with a descriptor of musical quality and calculates averages for the $0.5,1$ and 2 $\mathrm{kHz}$ bands. On the other hand, Jordan ${ }^{12}$ measures $\mathrm{C}_{80}$ in a number of prestigious European concert halls where the acoustic conditions for two octaves $(0.5$ and $1 \mathrm{kHz})$ have already been subjectively evaluated. Gade ${ }^{8}$ aims to study the acoustic data averaged for locations and frequencies for these thirty-two concert halls and establish a correlation with architectural design variables. Gade nevertheless concluded that $\mathrm{C}_{80}$ is strongly affected by room geometry.

Concerning the acceptable values of these parameters and tolerance intervals, we must emphasize that literature on acoustics has much more information for the clarity index than for the definition index in spite of the close correlation between them. In this sense, Marshall ${ }^{11}$ proposes $-2 \mathrm{~dB}-+2 \mathrm{~dB}$ as an acceptable range, and Jordan ${ }^{12}$ proposes not to exceed 4-7 dB for the maximum variation of $\mathrm{C}_{80}$ from one point to another in a room.

\section{MEASUREMENTS DETAILS}

All measurements were made in unoccupied churches and no corrections for occupancy were applied because our main aim is to analyse the behaviour of this architectural typology. The furniture consisted in wooden pews with low absorption, which may suggest greater attenuation depending on the degree of occupation because of an increase in audience plane absorption. All the churches are basically symmetrical about a central axis, and receiver positions were distributed uniformly throughout the audience seating area. In Figure 1 we show the ground plan, the longitudinal section, and the cross section of Santa Marina and San Marcos churches. 


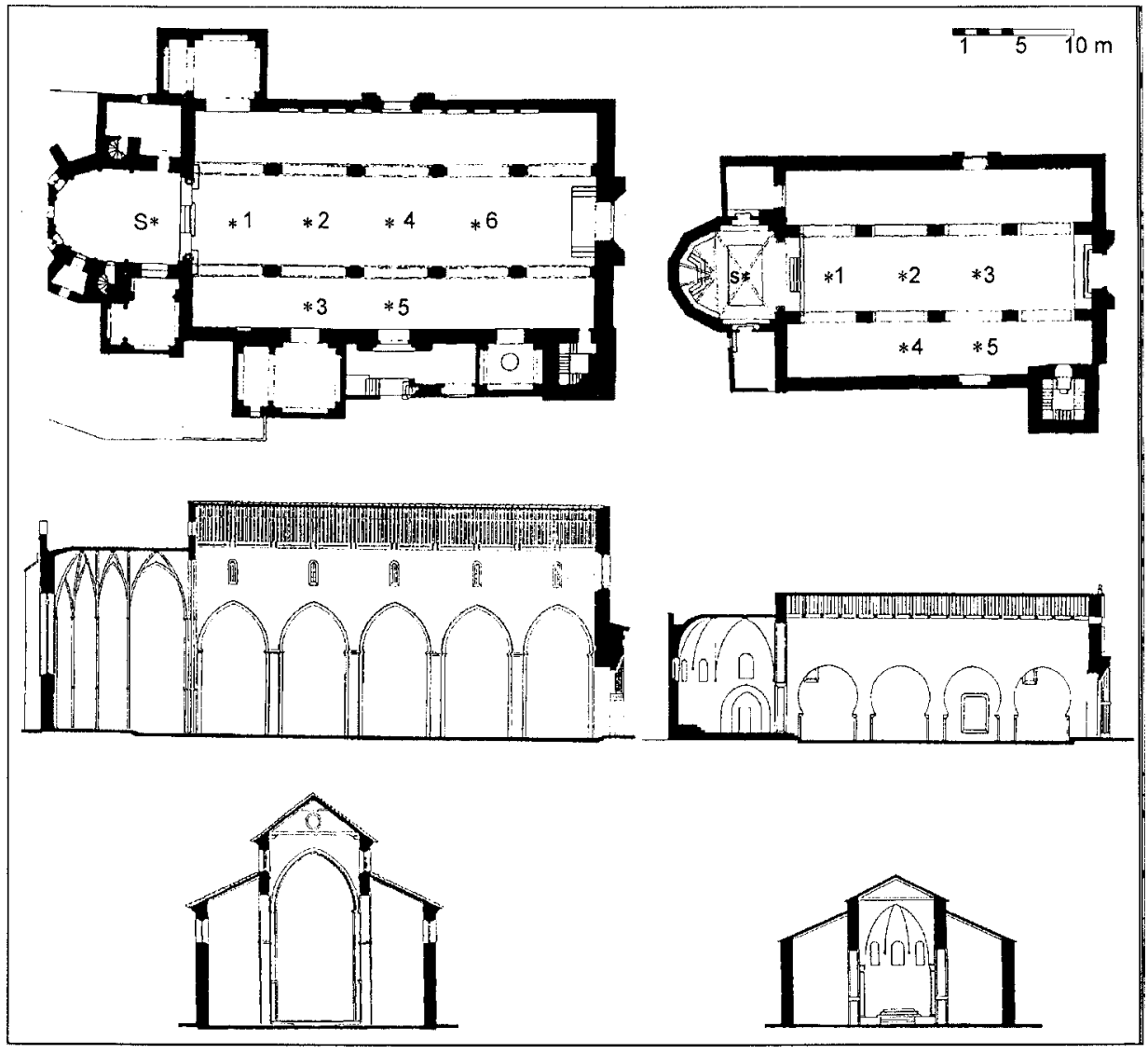

Figure 1. Ground plan with its reception points (top), longitudinal (middle) and cross section (bottom) of Santa Marina (left) and San Marcos (right) churches.

Two types of measurements were carried out: impulse measurements and steady-state measurements. The steady-state sound levels in these places were obtained using a reference source $(B \& K 4205)$ placed on the altar. These results have been published elsewhere ${ }^{13}$ and will be discussed later.

Impulsive signals were generated by firing a blank cartridge from a $9 \mathrm{~mm}$ pistol at the place where the source would be located in normal use. At each reception point the microphone signal was recorded using a Sony PC 204 DAT. In all cases, omnidirectional B\&K 4165 microphones were used with their respective preamplifiers and polarization sources from the same manufacturer.

The first stage of the analysis is laboratory processing of the signals using a B \&K 2133 analyser to find reverberation time $T$ in the bands of interest with Schroder's integrated impulse method. ${ }^{14.15}$ The second stage of the analysis requires the conversion of individual 
analogue recordings to a "wav" file using a PC Sound Blaster AWE34 sound card at a sampling frequency of $44.1 \mathrm{kHz}$. Afterwards, these data were processed with the MATLAB language to separate the range of interest (50-80 ms) and obtain the indices.

\section{THEORETICAL MODELS}

The acoustical indices are defined as follows by Reichardt ${ }^{16}$ (1975) for music and Thiele ${ }^{17}$ (1953) for speech:

$$
C_{80}=10 \log \left\{\frac{\int_{0}^{80} g(t)^{2} d t}{\int_{80}^{\infty} g(t)^{2} d t}\right\} \quad(d B), \quad D_{50}=100 \%\left\{\frac{\int_{0}^{50} g(t)^{2} d t}{\int_{0}^{\infty} g(t)^{2} d t}\right\}
$$

where $g(t)$ is the impulse response and $t=0$ coincides with the arrival time of the direct sound to the observation point. These indices can be determined in broadband or in octave band after having been filtered from the impulse response signal.

In the classical diffuse field model, there are no variations in sound level while we are within the reverberant field. In music auditoria or concert halls, however, levels generally do continue to decrease with increasing distance beyond the critical distance. Therefore, Barron et al., ${ }^{5,9,18}$ to predict total pressure levels and early to late sound/energy ratios (as clarity and definition), divide the acoustic energy received at each point into three components, all of which depend on source-receiver distance $r$ : direct sound $\boldsymbol{d}$, reflected sound in the first $\tau \mathrm{ms} \boldsymbol{e}_{r}$, and late reflected sound with a delay greater than $\tau \mathrm{ms} \boldsymbol{l}, \tau=80 \mathrm{~ms}$ for clarity and $\tau=50 \mathrm{~ms}$ for definition. So we would write for $C$ and $D$ :

$$
C=10 \log \left(\frac{d+e_{r}}{l}\right), \quad D=100 \%\left(\frac{d+e_{r}}{d+{ }_{r}+l}\right)
$$

In a recent paper on sound pressure levels measured in these Mudejar-Gothic churches, Sendra et $a l .{ }^{13}$ proposed some modifications to Barron's equations for $\boldsymbol{d}, \boldsymbol{e}_{r}$ and $\boldsymbol{l}$ to take into account measured attenuation in the reverberant field in this type of spaces. This modified model also maintains the same separation of energy as Barrons model as well as the exponential decay distance dependence for early and late acoustic energy, but it introduces in these exponentials some $\left\langle\beta_{\mathrm{i}}>\right.$ coefficients reached through nonlinear regression from the experimental values for each octave band $i$ and averages them for all churches.

Thus for the $i$ octave band we would have:

$$
e_{r_{i}}=\frac{31200 T_{i}}{V} e^{-\frac{\left\langle\beta_{i}\right\rangle r}{T_{i}}}\left(1-e^{-\frac{13.82 r}{T_{i}}}\right) ; \quad l_{i}=\frac{31200 T_{i}}{V} e^{-\frac{\left\langle\beta_{i}\right\rangle r}{T_{i}}} e^{-\frac{13.82 t}{T_{i}}}
$$

This study ${ }^{13}$ clearly shows on one hand the acceptable correlation that exists for acoustic levels measured at different source-receiver distances and the theoretical behaviour expected, and on the other the discrepancy with Barrons premises. These last commented discrepancies are shown graphically in Figure 2, that is reproduced of our previous work. ${ }^{13}$ 

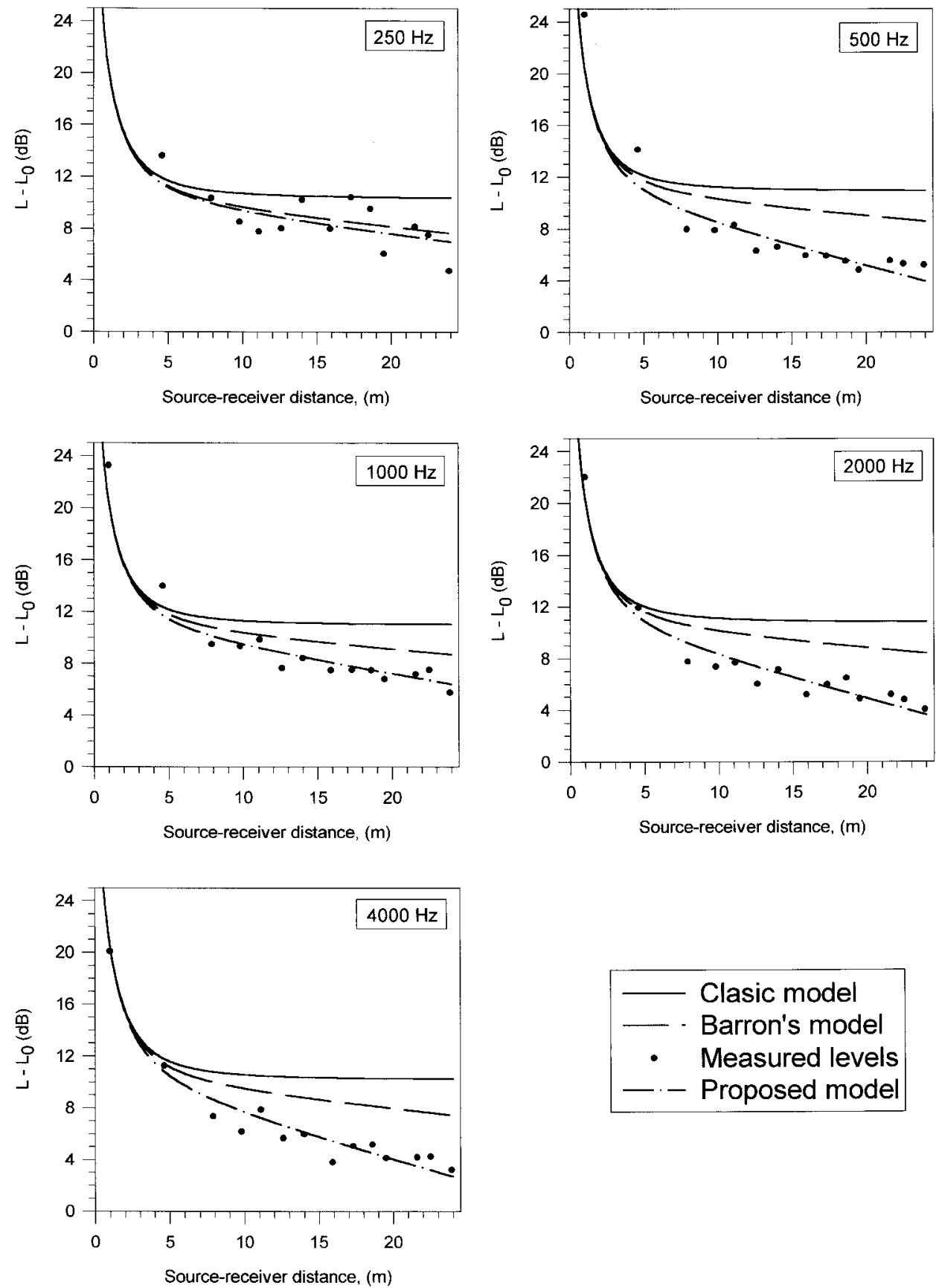

Figure 2. Sound pressure level $\mathrm{L}-\mathrm{L}_{0}(\mathrm{~dB})\left(\mathrm{L}_{0}\right.$, direct level under free field conditions at $\left.10 \mathrm{~m}\right)$ versus source-receiver distance (m) for the different octave bands in Santa Catalina church. 
Those facts led us to believe this could also happen with the objective acoustic clarity and definition indices, with the subsequent possibility of predicting their values in this architectural typology with no other premises than their geometry and $T_{i}{ }^{19}$

Based on Equations (2) and (3), we obtain for clarity a sa function of source-receiver distance $r$ :

$$
C_{80}=10 \log \left(\frac{V e^{\frac{\left(\beta_{i}\right) r+13.82 \tau}{T_{i}}}}{312 T_{i} r^{2}}+e^{\frac{13.82 \tau}{T_{i}}}-1\right) \quad \text { with } \tau=80 \mathrm{~ms}
$$

Likewise for the definition:

$$
D_{50}=100 \%\left(1-\frac{\left(31200 T_{i} / V\right) e^{-\frac{\left(\beta_{i}\right\rangle r+13.82 \tau}{T_{i}}}}{\frac{100}{r^{2}}+\frac{31200 T_{i}}{V} e^{-\frac{\left\langle\beta_{i}\right\rangle r}{T_{i}}}}\right) \quad \text { with } \tau=50 \mathrm{~ms}
$$

where $V$ is the volume and $T_{i}$ is the reverberation time for octave band $i$.

Considering Equations (4) and (5), we must emphasize that both functions $C(r)$ and $D(r)$ show a minimum at the same value of $r\left(r^{\prime}=2 T \sqrt{ }<\beta_{i}>\right)$. Also in Barron's revised theory, a very moderate minimum would be obtained for $C_{B}$ and $D_{B}$, in this case at a reception point distance $r_{B}^{\prime}=50 T$ in which $T$ is again the reverberation time, in other words, the deader the room, the shorter the distance. Both $r^{\prime}$ or $r_{B}^{\prime}$ are usually located outside the room and, according to the data of $\left\langle\beta_{\mathrm{i}}\right\rangle$ (see Table 1), it can be expected that $r^{\prime}<r_{B}^{\prime}$. Nevertheless, $r$ values can be found within the limits of the deadest churches, as occurs in San Vicente church at $2 \mathrm{kHz}\left(r^{\prime}=28 \mathrm{~m}\right)$ and at $4 \mathrm{kHz}\left(r^{\prime}=23.3 \mathrm{~m}\right)$ or Santa Catalina church at $4 \mathrm{kHz}\left(r^{\prime}=24.2 \mathrm{~m}\right)$. Finally, it must be said that this minimum does not appear when we use these expressions to predict the stationary pressure levels.

\section{EXPERIMENTAL RESULTS AND DISCUSSION}

Figure 3 shows the behaviour of $\mathrm{C}_{80}(\mathrm{~dB})$ on the left and $\mathrm{D}_{50}(\%)$ on the right as a function of source-receiver distance $r(\mathrm{~m})$ between $250 \mathrm{~Hz}-4000 \mathrm{~Hz}$ for the eight churches studied. The same graphics show the theoretical curves of these parameters obtained through Equations (4) and (5), with $<\beta_{\mathrm{i}}>$ calculated as mentioned above.

The experimental data are too far out to be fitted by the application of simple diffusefield theory, so the theoretical curves obtained by this classical model are not shown to avoid confusion in the figures. 

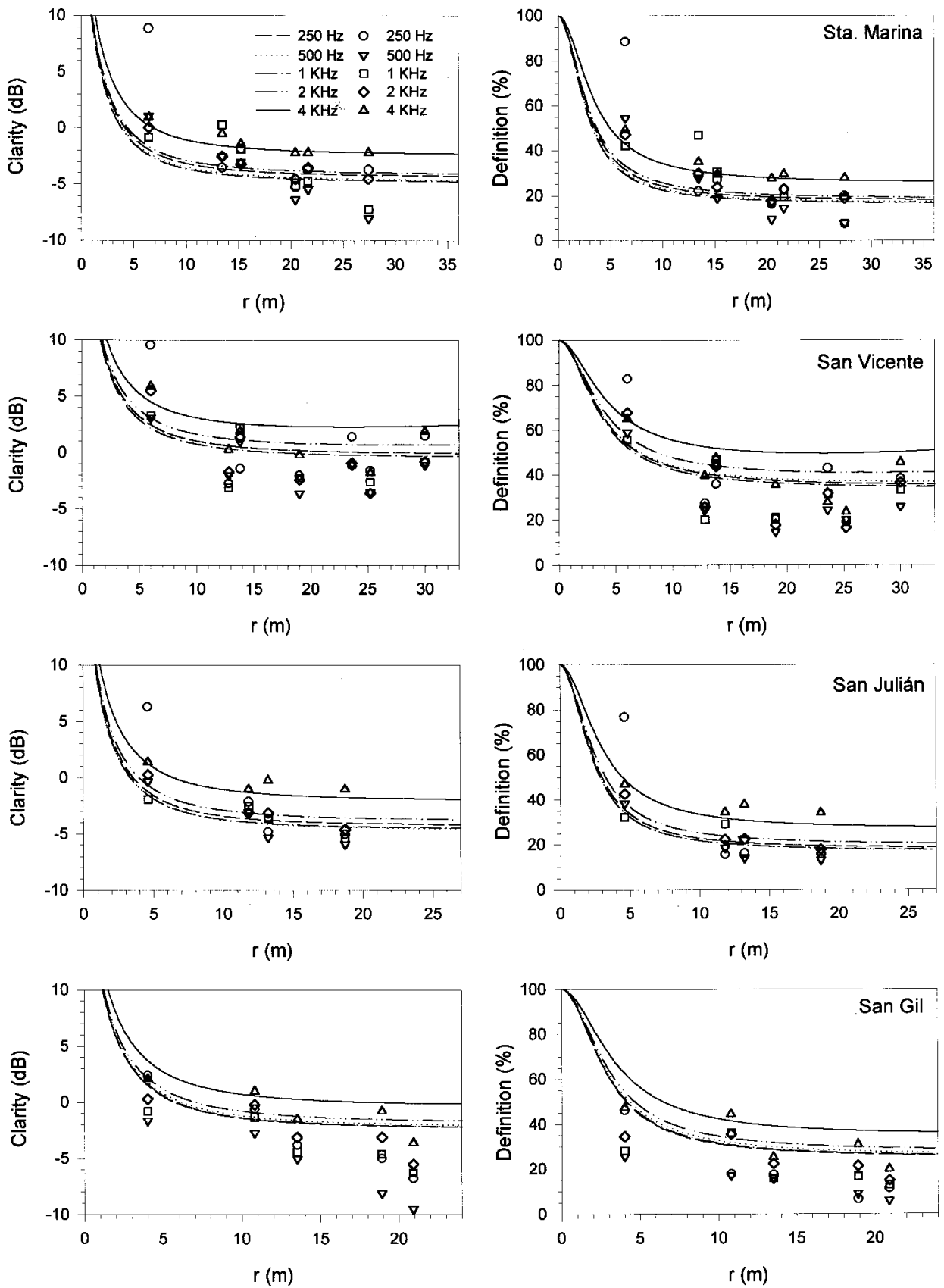

Figure 3. Clarity (dB) and definition (\%) versus distance $\mathrm{r}(\mathrm{m})$ in four churches: Santa Marina, San Vicente, San Julián and San Gil at each octave band. Symbols: measured data. Solid and dotted lines: theoretical models. 

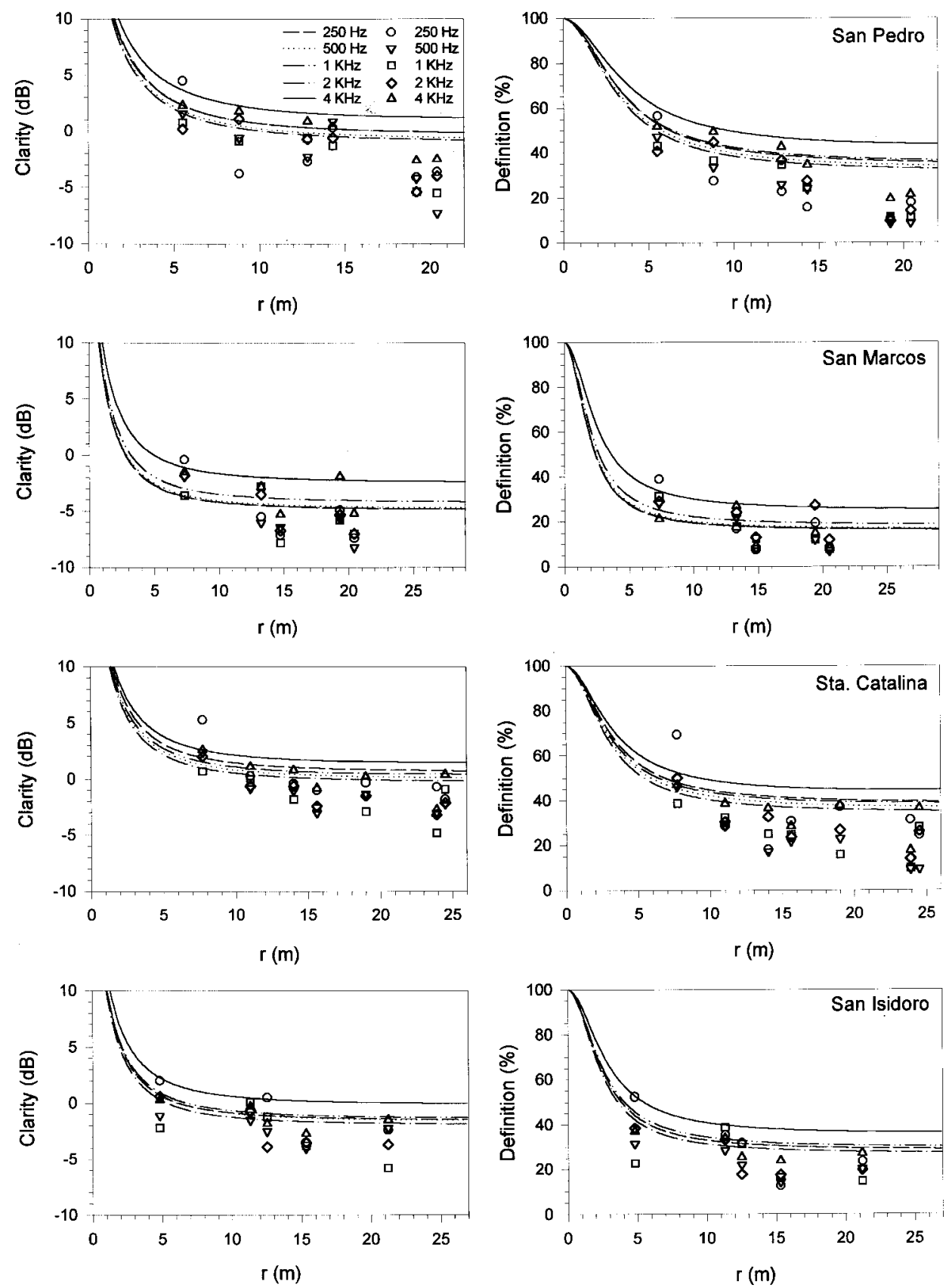

Figure 3 cont. Clarity (dB) and definition (\%) versus distance $r(m)$ in the last four churches: San Pedro, San Marcos, Santa Catalina and San Isidoro at each octave bands. Symbols: measured data. Solid and dotted lines: theoretical models. 


\section{Table 1}

\section{Significant data on Mudejar-Gothic churches}

$\begin{array}{lccccccccc} & \text { Santa } & \text { San } & \text { San } & \text { San } & \text { San } & \text { San } & \text { Santa } & \text { San } & \\ \text { Param. } & \text { Marina } & \text { Vicente } & \text { Julián } & \text { Gil } & \text { Pedro } & \text { Marcos } & \text { Catalina } & \text { Isidoro } & \left\langle\beta_{\mathrm{i}}>\right. \\ \mathrm{V}\left(\mathrm{m}^{3}\right) & 8696 & 6915 & 6226 & 6200 & 6108 & 4763 & 4362 & 3947 & \\ \mathrm{~S}\left(\mathrm{~m}^{2}\right) & 3988 & 3290 & 2984 & 2931 & 2758 & 2671 & 2251 & 2270 & \\ \mathrm{~d}_{\mathrm{mx}}(\mathrm{m}) & 36 & 33 & 27 & 24 & 22 & 29 & 26 & 27 & \\ \mathrm{r}_{\mathrm{a}}(\mathrm{m}) & 2.76 & 3.87 & 2.40 & 3.03 & 3.46 & 2.02 & 3.12 & 2.50 & \\ \alpha & 0.09 & 0.19 & 0.09 & 0.14 & 0.18 & 0.07 & 0.18 & 0.12 & \\ \mathrm{~T}_{1}(\mathrm{~s}) & 3.62 & 1.71 & 3.57 & 2.49 & 1.76 & 4.01 & 1.50 & 2.13 & \\ \mathrm{~T}_{2}(\mathrm{~s}) & 3.96 & 1.81 & 3.89 & 2.48 & 1.98 & 3.95 & 1.72 & 2.21 & \\ \mathrm{~T}_{3}(\mathrm{~s}) & 4.00 & 1.82 & 3.81 & 2.50 & 1.99 & 4.01 & 1.75 & 2.30 & \\ \mathrm{~T}_{4}(\mathrm{~s}) & 3.57 & 1.68 & 3.34 & 2.35 & 1.87 & 3.57 & 1.67 & 2.14 & \\ \mathrm{~T}_{5}(\mathrm{~s}) & 2.62 & 1.40 & 2.44 & 1.87 & 1.56 & 2.58 & 1.45 & 1.76 & \\ \mathrm{~T}_{\text {broad }} & 3.92 & 1.73 & 3.74 & 2.45 & 1.94 & 3.90 & 1.59 & 2.22 & \\ \beta_{1} & 0.05 & 0.06 & 0.05 & 0.07 & 0.04 & 0.10 & 0.05 & 0.06 & 0.06 \\ \beta_{2} & 0.13 & 0.08 & 0.11 & 0.13 & 0.09 & 0.14 & 0.12 & 0.11 & 0.11 \\ \beta_{3} & 0.09 & 0.07 & 0.06 & 0.10 & 0.07 & 0.10 & 0.08 & 0.08 & 0.08 \\ \beta_{4} & 0.13 & 0.10 & 0.13 & 0.14 & 0.11 & 0.15 & 0.12 & 0.12 & 0.12 \\ \beta_{5} & 0.13 & 0.10 & 0.13 & 0.13 & 0.11 & 0.20 & 0.11 & 0.12 & 0.12 \\ \beta_{\text {broad }} & 0.13 & 0.08 & 0.12 & 0.11 & 0.10 & 0.14 & 0.08 & 0.10 & 0.11\end{array}$

The most significant geometric and acoustic parameters of the churches analysed are listed in Table 1: volume $V$, interior surface $S$, maximum source-receiver distance $d_{m x}$, acoustic radius $r_{a}$, mean estimated absorption coefficient $\alpha$, measured reverberation times for the octave bands between 250 and $4000 \mathrm{~Hz}$ and in broadband $T_{i}$, and adjustment parameters $\beta_{\mathrm{i}}$ and $\left\langle\beta_{\mathrm{i}}>\right.$.

After considering the results, we would like to point out:

The parameters at each receiver are relatively disperse. Bradley ${ }^{20}$ also observed this in his paper on the $R$ index (Running Liveness, reverberant to early sound ratio), obtained from the response to the impulse in concert halls with similar reverberation times. This author uses averages for the $250-500 \mathrm{~Hz}$ and $2-4 \mathrm{kHz}$ frequency ranges.

Parameter $\mathrm{C}_{80}$ has a spatial and spectral pattern similar to those obtained by $\mathrm{Lam}^{21}$ at frequencies of $125 \mathrm{~Hz}$ and $1 \mathrm{kHz}$ when he studies the physical scale models of rectangular and fan-shaped auditoria.

In the $4 \mathrm{kHz}$ band, a unique increase in both indices is usually seen in the theoretical model. This increase is mainly due to the fact that there is a sharp drop in reverberation times in this octave in all churches because of air absorption at these frequencies (see Table 1). This increase matches the experimental results for most churches.

Greater attenuations over distance than allowed by the model are observed, especially for the deadest churches, as shown in the graphs for San Vicente and Santa Catalina churches.

The $\mathrm{C}_{80}$ early to late ratio undergoes changes of sign at different frequencies at the same reception point. This also occurs with the same frequency at different positions within the 
same church. We should point out that, in San Marcos church, $\mathrm{C}_{80}$ remains negative at all the points studied, indicating a large contribution of late sound energy in this church. In fact, this is the only church without a wooden ceiling over the main nave. Because of its bad state of repair, the wooden ceiling was replaced by a roof of ceramic flooring blocks supported by metal purlins, causing the reflections off the ceiling to reach the audience area with significant intensities and delay.

Since other authors (Perloson et al. ${ }^{3}$ ) have discovered a high degree of correlation among objective acoustic parameters, especially among those that measure the early to late energy relations, we wanted to compare the $\mathrm{C}_{80}$ values with the $\mathrm{D}_{50}$ values in Figure 4 for all the measurements taken (210 pairs of values). Likewise, the regression line is shown by the equation:

$$
D_{50}=4.06 C_{80}+34.8
$$

and has a 0.82 correlation coefficient. Although the correlation is close, it is somewhat less than that found by other researchers. This should not surprise us if we take into account that those results refer to rooms that, unlike the churches we are studying, were designed with acoustic criteria in mind.

The range, mean value and standard deviation for the audience area in the churches evaluated are shown in Table 2. The dispersions and intervals for the values are similar to those described by Perloson $e t a l .{ }^{3}$ in their study of rooms with very different characteristics. As in their study, range $\delta$ is around three or four times standard exist in the San Vicente and Santa Catalina churches and the worst exist in San Marcos. The average values for all the churches are listed in the row entitled "typology".

Table 2

Maximum and minimum values, range, mean values and standard deviation for both acoustic indices in the churches

\begin{tabular}{lrrrrrrrrrr} 
& \multicolumn{4}{c}{ Clarity $(\mathrm{dB})$} & \multicolumn{9}{c}{ Definition $(\%)$} \\
Church & Max. & \multicolumn{1}{c}{ Min. } & \multicolumn{1}{c}{$\delta$} & \multicolumn{1}{c}{$C$} & $\sigma$ & Max. & Min. & $\delta$ & $D$ & $\sigma$ \\
Santa Marina & 0.3 & -8.0 & 8.3 & -3.5 & 1.99 & 46.9 & 7.8 & 39.1 & 22.9 & 8.8 \\
San Vicente & 2.2 & -3.6 & 5.8 & -0.9 & 1.74 & 47.8 & 14.9 & 32.9 & 30.2 & 10.2 \\
San Julián & -0.2 & -5.9 & 5.7 & -3.3 & 1.78 & 37.9 & 13.1 & 23.8 & 22.1 & 8.1 \\
San Gil & 2.4 & -9.5 & 11.9 & -2.9 & 3.06 & 47.5 & 6.1 & 41.4 & 23.3 & 12.0 \\
San Pedro & 4.5 & -7.3 & 11.8 & -1.4 & 2.76 & 56.6 & 8.6 & 48.0 & 28.4 & 14.3 \\
San Marcos & -0.4 & -8.2 & 7.8 & -4.8 & 2.23 & 39.0 & 7.1 & 31.9 & 17.4 & 9.0 \\
Santa Catalina & 5.3 & -4.8 & 10.1 & -0.7 & 1.96 & 69.4 & 9.3 & 60.1 & 29.0 & 12.5 \\
San Isidoro & 2.0 & -5.8 & 7.8 & -1.8 & 1.82 & 52.4 & 12.6 & 39.8 & 26.8 & 9.6 \\
Typology & 5.3 & -9.5 & 15.8 & -2.2 & 2.61 & 69.4 & 6.1 & 63.5 & 25.5 & 11.6
\end{tabular}

Since we hope to analyse the possibilities of proposing a model for the typology, the theoretical curves in Figure 3 were obtained from the values of $\left\langle\beta_{i}>\right.$ averaged for all the churches. All the churches show a very similar spectral and spatial tendency in spite of the 


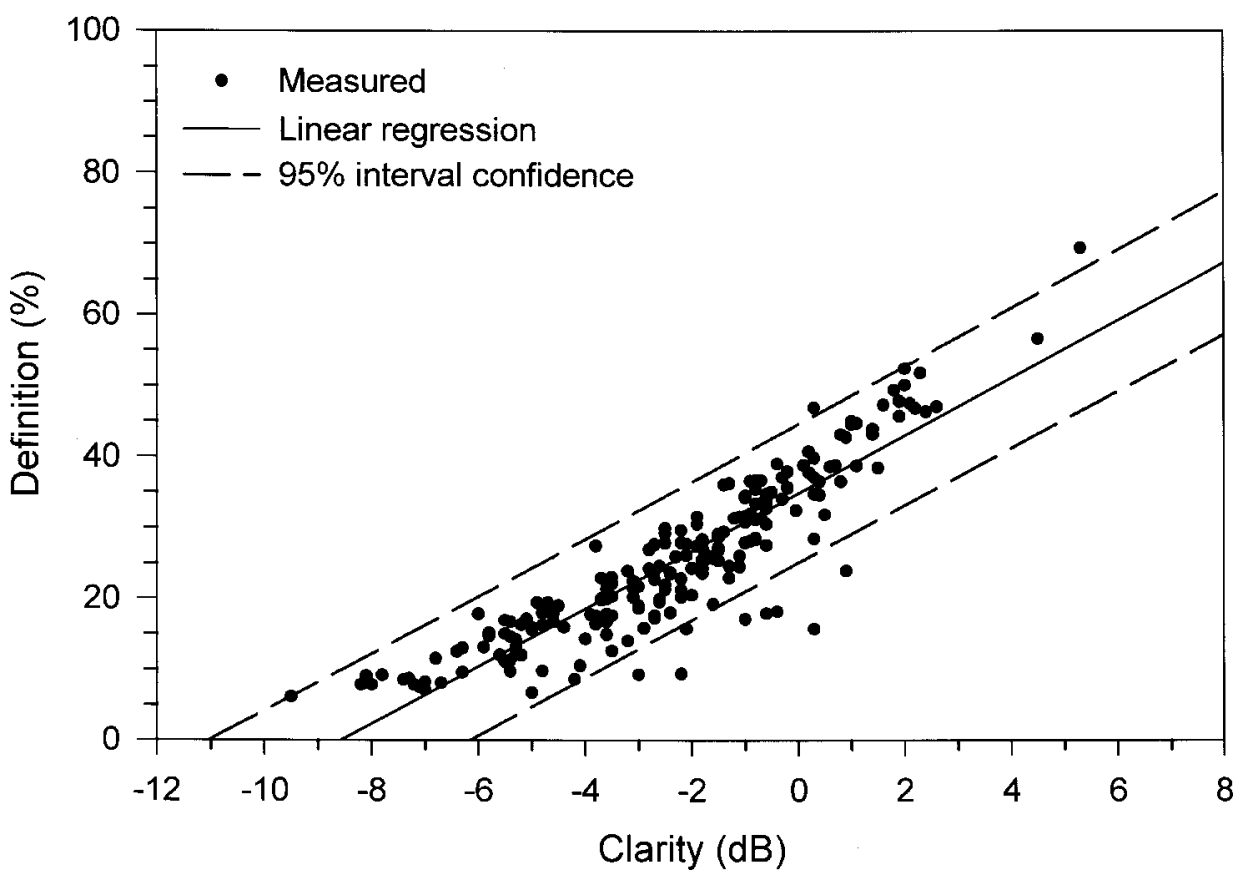

Figure 4. Definition (\%) plotted against clarity (dB).

fact that the values of $<\beta>$ range between 0.06 (at $250 \mathrm{~Hz}$ ) and 0.12 (at 2 and $4 \mathrm{kHz}$ ). The specific differences among these values for the same church or among values for different buildings are indicated by the reverberation time at different frequencies (the uniqueness of the $4 \mathrm{kHz}$ band has already been pointed out), and by the variations of $\mathrm{T}$ and $\mathrm{V}$ from one church to another.

On the other hand, the dispersion of values measured in situ at each point for the octave bands under study is much greater, so we have to renounce in principle the possibility of establishing a simple spectral model to easily calculate these indices. However, given the tendency of the experimental data, the possibility exists of predicting behaviour based on distance. Therefore, Figure 5 shows the values of the indices measured processed in wide band and the curves based on Barron's model and the model suggested based on Equations (4) and (5).

We must point out that the broadband values for clarity and definition are similar to those obtained by averaging the $500 \mathrm{~Hz}, 1 \mathrm{kHz}$ and $2 \mathrm{kHz}$ bands, as suggested by some researchers. ${ }^{9}$ These results have been omitted to avoid tedious length.

We can observe that the difference between Barron's model and the model proposed is minimal for predicting these indices. However, as we already mentioned, the result is different when we calculate the stationary levels as a function of distance.

Therefore, it seems to make no difference which one is used, although either will only 

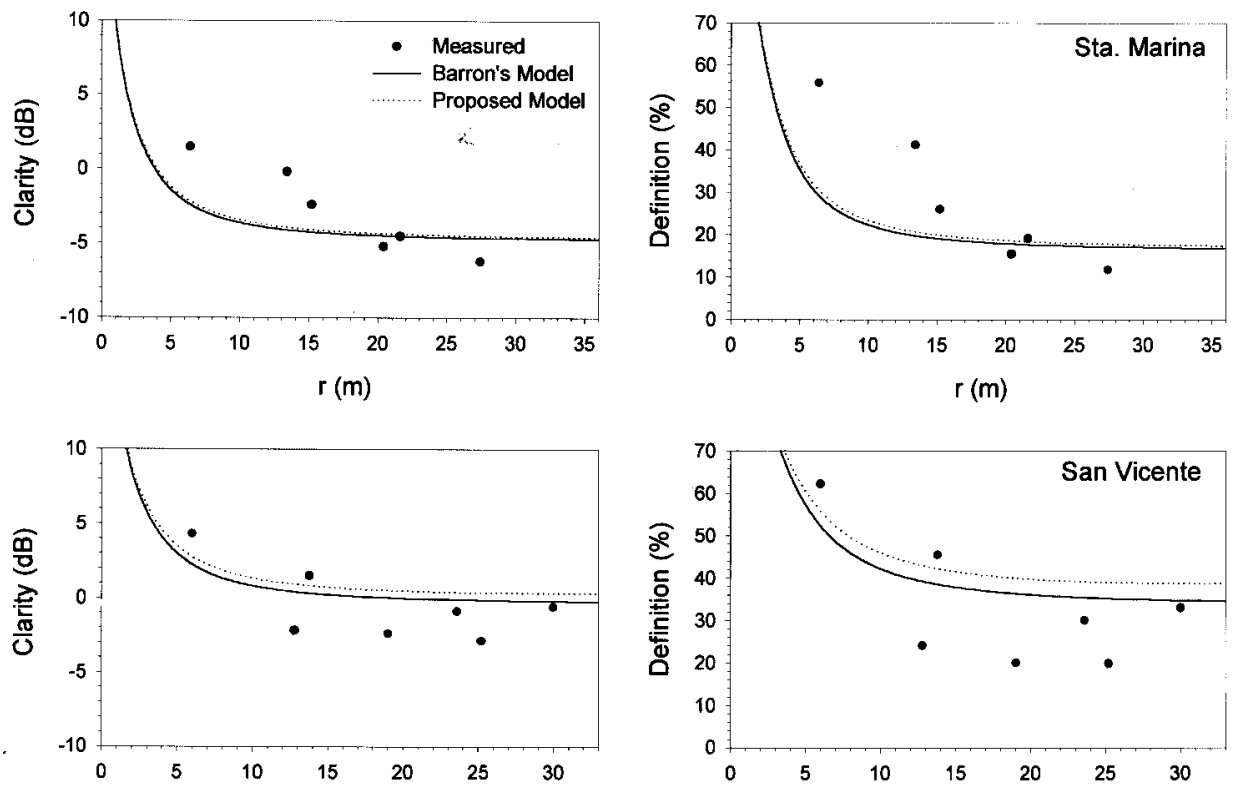

$r(m)$

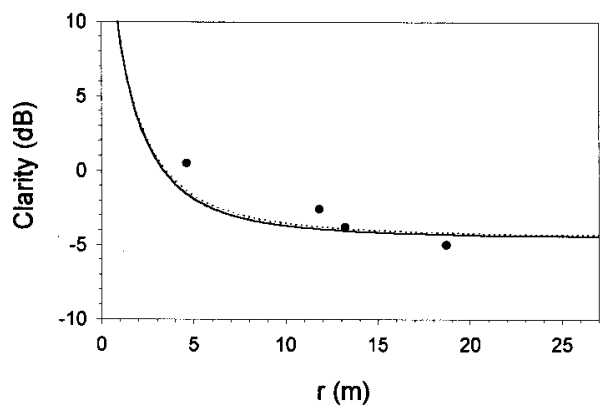

$r(m)$
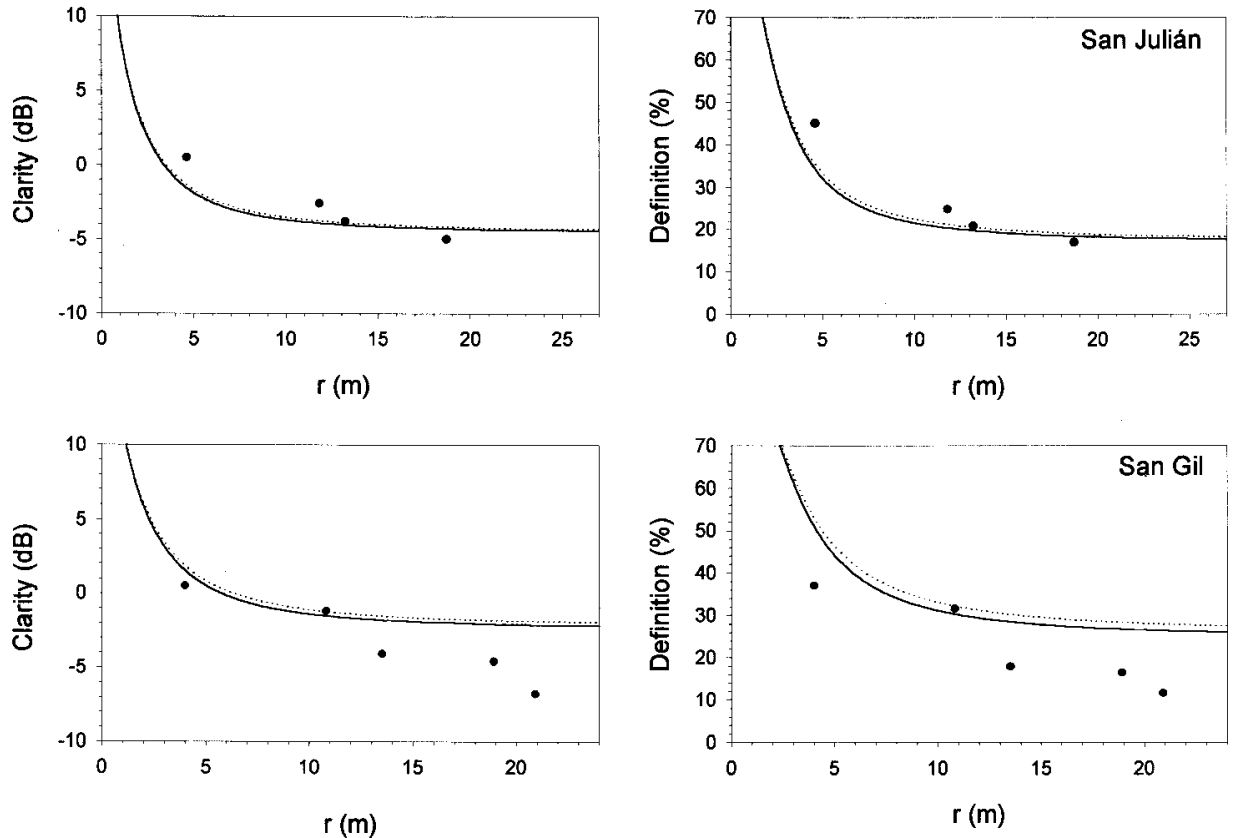

Figure 5. Clarity (dB) and definition (\%) plotted against distance $r(m)$ in four churches: Santa Marina, San Vicente, San Julián and San Gil at broadband. Symbols: measured data. Solid and dotted lines: theoretical models. 

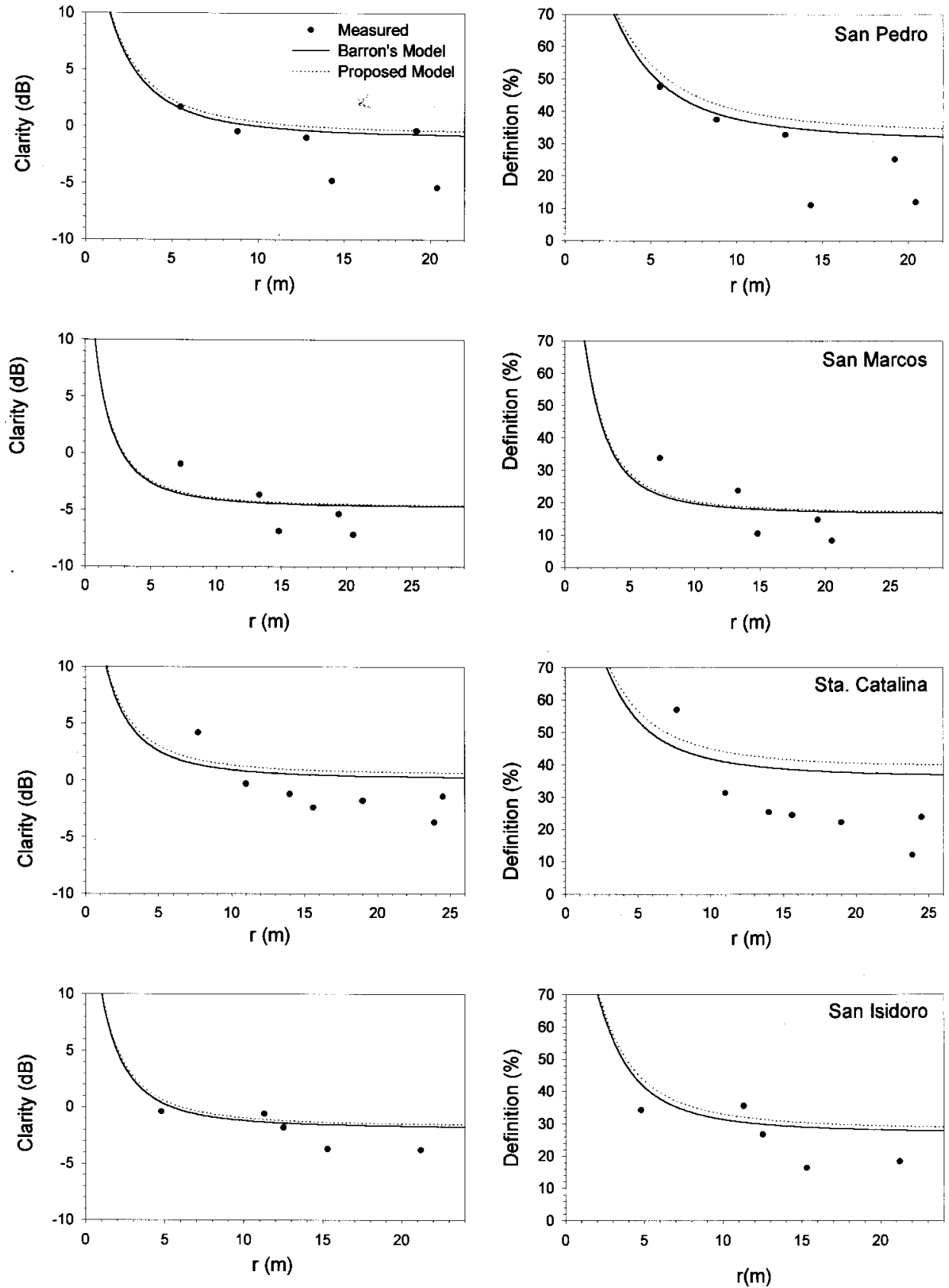

Figure 5 cont. Clarity $(\mathrm{dB})$ and definition $(\%)$ plotted against distancer $(\mathrm{m})$ in the last four churches: San Pedro, San Marcos, Santa Catalina and San Isidoro at broadband. Symbols: measured data. Solid and dotted lines: theoretical models. 
show tendencies because the values of these indices vary greatly from one place to another and cannot be incorporated into a typological model such as the one proposed. We should point out that, even if we taken the values of $\beta$ for each church instead of the averages, the model cannot describe the variations observed in the data obtained in situ. Consider, once again, the limited effect of modifying the attenuation constant according to distance in Barron's exponentials and in the model proposed.

The experimental results shown above as a function of the local variations are also supported by the values calculated for definition (\%) and clarity (dB) by computer simulation carried out in our laboratory with the RAYNOISE acoustic software in the "map calculation" mode. We will not supply details because of space and some of these results have been presented recently.2

Finally, we would like to point out that results similar to those stated here were obtained by Vela ${ }^{23}$ in a complete and rigorous study that includes experimental data and results simulated with the software mentioned in the Gayarre Theatre in Pamplona.

\section{CONCLUDING REMARKS}

Although the modifications of Barron's model have helped us develop a typological model that efficiently predicts stationary reverberant field attenuations over distance for different octave bands, we have found that such efficiency is much more limited for predicting indices based on early to late energy ratios. In fact, it seems sufficient to give the broadband set of values for these indices. Furthermore, Barron's model provides results similar to those of our model. These only show trends because significant variations of index values among relatively close positions are impossible to incorporate into simple analytical models such as Barron's or the one we have proposed. ${ }^{13}$

At present we are carrying out more exhaustive tests in other types of buildings to evaluate the scope of the conclusions drawn in this paper.

We also hope to process impulse responses from Mudejar-Gothic churches, weighting these signals with some weighting factors for the different frequencies. Lochner et al. ${ }^{24}$ propose a similar method for calculating the articulation index when they evaluate the incidence of the early reflections as a function of delay and their relative amplitude with respect to direct sound.

Since we have data related to intelligibility tests using the RASTI index, we would also like to analyse them to establish the degree of correlation between this index on the one hand and the weighted early to late energy ratio, clarity and definition on the other hand.

\section{ACKNOWLEDGEMENTS}

We would like to thank Dr Juan José Sendra for directing our interest toward the acoustical conditions of Mudejar architecture and for his help in preliminary data processing. We are also grateful to Dr Antonio Vela and to Dr Miguel Arana by supplying us with the data from their work. 


\section{REFERENCES}

1. Sendra, J.J. and Zamarreño, T. (1995). El campo sonoro en las iglesias Gótico-Mudéjares con cubierta de madera: Aplicación del modelo de Barron, Proceedings of Tecni-Acustica '95, XXVI Jornadas Nacionales de Acústica, La Coruña, Spain, 2, p. 87.

2. Sendra, J.J. and Navarro, J. (1997). La evolución de las condiciones acústicas en las iglesias: del Paleocristiano al Tardobarroco, Textos de Doctorado I.U. de Ciencias de la Construcción, E.T.S.A., Universidad de Sevilla, p. 32.

3. Perloson, X., Vian, J.P. and Polack, J.D. (1992). On the variability of room acoustical parameters: reproducibility and statistical validity, Appl. Acoust., 9: 175.

4. Barron, M. (1995). Balcony overhangs in concert auditoria, J. Acoust. Soc. Am., 98, p. 2580.

5. Barron, M. (1973). Growth and decay of sound intensity in rooms according to some formulae of geometric acoustics theory, J. Sound Vib., 27: 183.

6. Miles, R.N. (1984). Sound field in a rectangular enclosure with diffusely reflecting boundaries, J. Sound Vib., 92: 203.

7. Pirn, R. (1992). Some objective and subjective aspects of three acoustically variable halls, Appl. Acoust., 35: 221.

8. Gade, A.C. (1990). The influence of architectural design on the acoustic of concert halls, Appl. Acoust., 31: 207.

9. Barron, M. and Lee, L.J. (1988). Energy relation in concert auditoriums, I, J. Acoust. Soc. Am., 84: 618.

10. Bradley, J.S. (1994). Comparison of concert hall measurements of spatial impression, J. Acoust. Soc. Am., 96: 3525.

11. Marshall, L.G. (1994). An acoustic measurement program for evaluating auditoriums based on the early/late sound energy ratio, J. Acoust. Soc. Am., 96: 2251.

12. Jordan, V.L. (1981). A group of objective acoustical criteria for concert hall, Appl. Acoust., 14: 253 .

13. Sendra, J.J., Zamarreño, T. and Navarro, J. (1997). An analytical model for evaluating the sound field in Gothic-Mudejar churches. Computational Acoustic and Its Environmental Application II. Computational Mechanics Publications, Southampton, p. 139.

14. Schroeder, M.R. (1965). New method of measuring reverberation time, J. Acoust. Soc. Am., 37: 409.

15. ISO-3382: 1997(E). (1997). Acoustic measurement of the reverberation time of rooms with reference to other acoustical parameters.

16. Reichardt, W., Abdel Alim, O. and Schmidt, W. (1974). Definition und Messgrundlage eines objetiven Masses zur Ermittlung der Grenze swischen brauchbarer und unbrauchbarer Durchsichtigkeit bei Musikdarbietung, Acustica, 32: 243.

17. Thiele, R. (1953). Richtungsverteilungund Zeitfolge der Schallruck Wurfe in Raumen, Acustica, 3: 291.

18. Barron, M. (1995). Bass sound in concert auditoria, J. Acoust. Soc. Am., 97: 1088.

19. Zamarreño, T., Galindo, M. and Girón, S. (1997). Predicción de indices acústicos en iglesias Gótico-Mudéjares, Proceedings of XXVI Reunión Bienal de la Real Sociedad Española de Fisica y Quimica, Las Palmas de Gran Canarias, Spain, p. 25.

20. Bradley, J.S. (1983). Experience with new auditorium acoustic measurement, J. Acoust. Soc. Am., 73: 2051.

21. Lam, Y.W. (1996). The dependence of diffusion parameters in room acoustics prediction model on auditorium sizes and shapes, J. Acoust. Soc. Am., 100: 2193.

22. Galindo, M., Zamarraño, T., Girón, S., Sendra, J.J. and Navarro, J. (1999). Simulated acous- 
tics fields in Mudejar-Gothic churches, 137th regular meeting of the Acoustical Society of America 2nd convention of the EAA: Forum Acusticum, Berlin, Germany, 14-19 March 1999.

23. Vela, A. (1996). Análisis de diferentes métodos de evaluación de la calidad acústica de un local: aplicación al teatro Gayarre de Pamplona, Tesis Doctoral, Universidad de Valencia, Spain.

24. Lochner, J.P.A. and Burger, F. (1964). The influence of relfection on auditorium acoustics, J. Sound Vib., 1: 426. 